\title{
Exploring Technical Quality Factors That Enhance Mobile Learning Applications Services Using Data Mining Techniques
}

Ahmad Abu-Al-Aish, Department of Computer Science, Jerash University, Jerash, Jordan

\begin{abstract}
Mobile learning (m-learning) has become an increasingly attractive solution for schools and universities that utilize new technologies in their teaching and learning setting. This study investigates the technical factors affecting the development of m-learning applications services from students' perspectives. It presents a model consisting of 12 technical factors, including content usefulness, scalability, security, functionality, accessibility, interface design, interactivity, reliability, availability, trust, responsiveness, and personalization. To evaluate the model, a questionnaire was designed and distributed to 151 students in Jerash University, Jordan. The results indicate that all technical factors have positive effects on learner satisfaction and overall m-learning applications service; however, the data mining analysis revealed that security and scalability factors exert a major impact on student satisfaction with m-learning applications services. This study gives insight for the future of developing and designing m-learning applications.
\end{abstract}

\section{KEYWORDS}

Data Mining Techniques, M-Learning, M-Learning Applications, M-Learning Deployment, M-Learning Implementation, Mobile Learning Application, Technical Factors, User Satisfaction

\section{INTRODUCTION}

In recent years, the rapid development in wireless and communication technologies and market forces have made mobile devices widespread and relatively cheap, with fast and easy internet access, mobility, and more convenience, including with regard to e-services such as e-commerce and educational applications such as mobile learning (m-learning) (Almaiah et al., 2016; Sarrab et al., 2015; Wu et al., 2012). M-learning is galvanizing technology utilization in higher education, enabling the delivery of learning materials anytime, anywhere, and providing a strong opportunity for students and lecturers to engage, communicate, collaborate, and share learning contents (Ali et al., 2012). Furthermore, using mobile technologies in learning environments can offer control over learning, portability in terms of time and place, and wide interaction (Jones et al., 2006; Traxler, 2009). The term 'm-learning' has come to encompass all of these attributes in a pedagogical context.

Technologies support learning and teaching are attracting many educators in different educational fields to provide more efficient learning and teaching methods (Virtanen et al., 2018). Many researchers investigated the benefits of m-learning for teaching and learning within schools and universities environments. M-learning has been utilized as a tool to support secondary school students learning basic programming concepts (Giannakoulas \& Xinogalos, 2018), to improve students learning ability

\section{DOI: 10.4018/IJICTE.20211001.oa14}

This article published as an Open Access article distributed under the terms of the Creative Commons Attribution License (http://creativecommons.org/licenses/by/4.0/) which permits unrestricted use, distribution, and production in any medium, provided the author of the original work and original publication source are properly credited. 
to discover new knowledge in learning natural science (Hung et al., 2014), learning resources in museums (wang et al., 2016), and learning contents and location information using active learning support system (ALESS) (Hsu et al., 2016). In addition, m-learning is an eminently suitable technology for application in conventional higher education course teaching. It supports collaborative learning, which is particularly useful in language learning as well as its general facilitation of ubiquitous learning services (Alnabhan et al., 2018; Huang et al., 2016; Troussas et al., 2014). It has been used to help undergraduate students learn computer programming (John \& Rani, 2015), facilitate learning computing and mathematics courses (Drigas \& Pappas, 2015; Oyelere \& Suhonen, 2016), and help nursing students in their practical training (Guo et al., 2007; Wu et al., 2012).

M-learning users try to find applications that satisfy their requirements for learning services. In other words, they demand services of necessary quality that improve their satisfaction to use m-learning applications (Kim and Ong, 2005). The quality of m-learning services has been evaluated in terms of the overall performance that affects student learning (Benhamida et al., 2017). The principle idea in learning environments is that the quality of services and user satisfaction are the key factors of successful learning and teaching processes. Quality of service is assayed in terms of users' perceptions of how good m-learning applications are (Sarrab et al., 2016). Delone and Mclean (2003) indicate that system quality influences user satisfaction towards systems. Many researchers clarify that factors related to system quality play a significant role in successful system deployment (Almarashdeh et al., 2010).

There is a shortage of research considering the technical quality aspects of m-learning applications services in higher education institutes. there are a few studies that discuss this topic. The novelty of this study is to explore and evaluate technical quality factors that help the development of m-learning applications in higher education environments. This can provide high quality services which motivate students, instructors, and decision makers to use and implement m-learning technology. The study contributes to m-learning researches by adding comprehensible and clear model that contains technical quality factors that should be consider while design and implement m-learning applications in higher education.

\section{RELATED RESEARCH}

M-learning offers a good opportunity for learning and teaching process. Several studies have investigated the design of m-learning applications in terms of pedagogical or technical aspects and issues (Oyelere et al., 2018). M-learning systems providing great service quality and stakeholder satisfaction are considered the main factor for a successful m-learning process in higher education environments (Sarrab et al., 2016). Al-Mushasha and Hassan (2009) investigated university students' perceptions about m-learning services' quality, students' satisfaction with m-learning services, and students' behavioral intention to utilize m-learning in their studies. They proposed a service quality model for m-learning in university context that measured ten technical factors derived from service quality, information quality, and system quality on overall students' perceived services quality. In addition, they measured the relationship between overall perceived quality, learner satisfaction, and behavioral intention. The results indicated that the technical factors of interface design, trust, content usefulness, content adequacy, ease of use, reliability, accessibility, and interactivity support m-learning services for university students. Furthermore, the results indicated that there is a relationship between overall perceived m-learning services and student satisfaction, and between student satisfaction and behavioral intention to use m-learning.

Almaiah et al. (2016) investigated the factors that enhance mobile learning system quality based on university students' perspectives. They presented and tested three frameworks for m-learning system based on quality factors. The three frameworks depend on three types of quality factors with eleven sub-quality factors: (1) information quality, concerning content usefulness and adequacy; (2) system quality, concerning functionality, accessibility, interactivity, interface design, and ease of use; 
and (3) service quality, including availability, personalization, trust, and responsiveness. The data were collected from a total 392 graduate and undergraduate students from five Jordanian universities. The results indicated that all quality factors supported high-quality of m-learning systems that meet student requirements and contribute to the successful deployment of m-learning system in higher educational institutes.

Sarrab et al. (2016) proposed and described a model that contains the technical aspects of mobile learning services quality. A group of technical quality factors was derived from mobile learning application previous studies, with concentration on mobile application software for learning and teaching. The model includes flexibility, scalability, usability, availability, quick response, maintainability, performance, functionality, reliability, connectivity, user interface, and security.

To validate the workability of the proposed model, the researchers examined the twelve components of the model (technical quality factors) with different and well-known mobile learning platforms empirically. Four case studies were investigated against the technical quality factors in order to determine which technical factor contributes to and enhances the development of m-learning application services in the education context. The case studies were the following m-learning systems: MOODEL, Blackboard, Schoology, and Edmodo. The results indicate that there are relationships between the overall technical aspects of the proposed model and learner satisfaction. In addition, the model supports the overall learning process by validating the technical aspects while control the quality of mobile learning deployed.

Other studies explored the factors that affect the continuous usage of m-learning service within higher education institutions. Glood et al. (2018) tested the effect of information quality, services quality, and compatibility on user satisfaction, and finally the continuous usage of m-learning. The findings indicated that information quality, services quality, and compatibility affect the usage of m-learning through user satisfaction. Furthermore, the findings suggest that m-learning service providers need to provide high quality information, good services, and compatibility to maintain the post adoption of m-learning services.

It is worth to mention that a lot of studies in m-learning field concentrate on m-learning acceptance using Technology acceptance model (TAM) (Liu et al., 2010) and Unified Theory of Acceptance and Use of Technology (UTAUT) (Abu Al-Aish \& Love, 2013; Venkatesh et al., 2003). The aim of these studies was to investigate user's behavioral attention toward use m-learning. Other studies aimed to build frameworks and models for m-learning system in education environment (Motiwalla, 2007) to discuss the benefit and challenged of m-learning. These models ignored the quality factors that could participate to successful use and implementation of m-learning in higher education institutes. However, there is a shortage of researches that considering the technical quality of m-learning application services. Therefore, this study aims to propose a model of technical quality factors that enhance m-learning application services, and to examine which of technical quality factors that have the most affect and contribute to the use and implementation of m-learning services in higher education environment. In addition, the data analysis in pervious researches utilized descriptive or multiple regression analysis to test the model designed or to evaluate the effectiveness of model factors through comparative studies with current m-learning platforms. The data analysis in this research utilize the data mining techniques that give more accurate results.

\section{TECHNICAL QUALITY FACTORS}

A model of technical quality factors was derived from literature review and developed based on software quality of m-learning applications (Almaiah et al., 2016; Al-Mushasha \& Hassan, 2009; Sarrab et al., 2016). The model addresses the most common and theoretical technical aspects of m-learning application services, such as content usefulness, scalability, security, functionality, accessibility, interface design, interactivity, reliability, availability, rust, responsiveness, and personalization. Figure 1 illustrates the model. 
Table (1) explains the related m-learning applications features for every technical factor and supporting references. These features are suggested from previous literature studies that explored mobile application software quality.

\section{RESEARCH METHODOLOGY}

This study utilized a quantitative questionnaire method to explore technical factors that enhance m-learning services. The questionnaire was designed from previous work to capture university students' feedback about the technical factor proposed in the model (Figure 1). The questionnaire contains questions about students' demographic information, and 33 items measuring 12 constructs.

The questionnaire was distributed to undergraduate students in the Faculty of Computer Science and Information Technology and the Faculty of Engineering, Jerash University. Students from different classes were invited to participate and complete the questionnaire in their class. A brief description about the study objectives and a definition of m-learning and its services were given by the researcher before students started answering the questionnaire. A total number of 151 responses were obtained. After the data were collected, a pre-processing of the data was conducting including data cleaning and data conversion. The next step was data set analysis using descriptive analysis and data mining techniques (simple K-means, expectation-maximization (EM), Apriori Association Algorithm and Multilayer Perceptron (MLP). finally, results representation. Figure 2 explain the object process diagram.

Figure 1. Proposed technical factors model

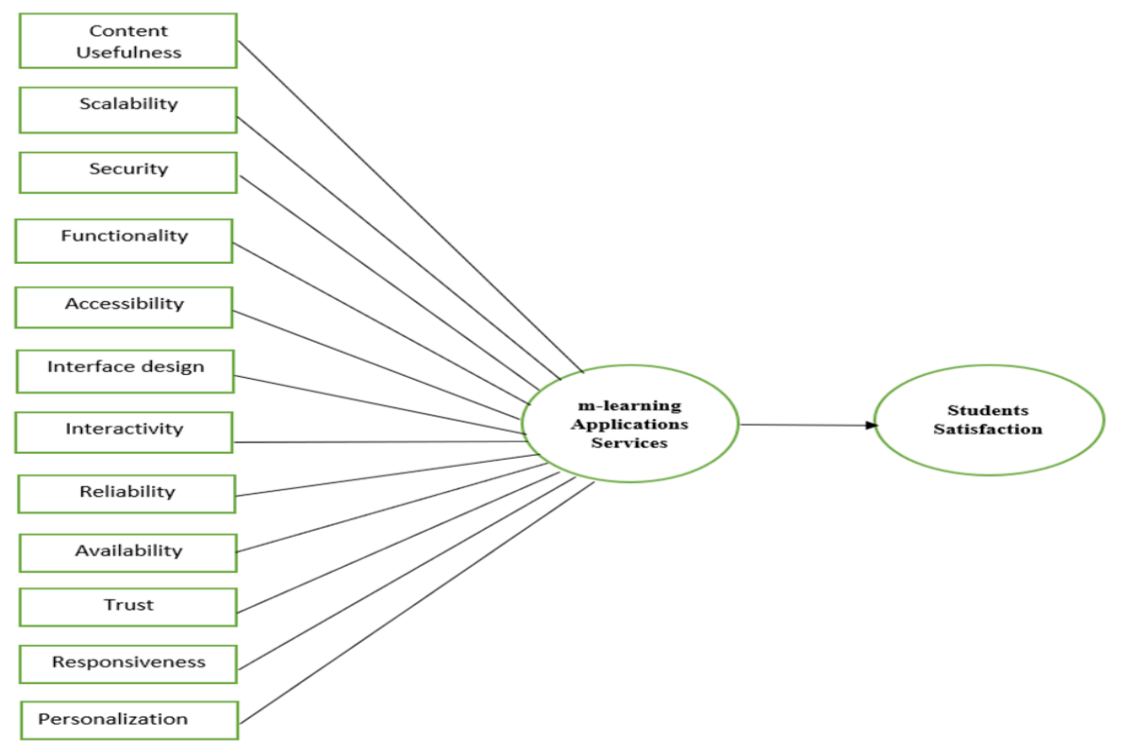


Table 1. Proposed model factors and related m-learning applications features

\begin{tabular}{|c|c|c|}
\hline Technical factor & Related m-learning applications features & Reference \\
\hline Content Usefulness & $\begin{array}{l}\text { Up-to-date, accurate content, that fits users' needs, including } \\
\text { multimedia and collaborative content. }\end{array}$ & Almaiah et al. (2016) \\
\hline Scalability & $\begin{array}{l}\text { Ability to accommodate and adapt changes made to the application, } \\
\text { ability to handle multiple types of contents and large number of users. }\end{array}$ & Wingkvist (2009) \\
\hline Security & $\begin{array}{l}\text { Keeping data confidentially, with integrity and privacy. Implementing } \\
\text { authentication and authorization. }\end{array}$ & Sarrab et al. (2016) \\
\hline Functionality & $\begin{array}{l}\text { Suitability, compliance, accuracy, interoperability, privacy, easy } \\
\text { navigation. }\end{array}$ & $\begin{array}{l}\text { Almaiah et al. (2016), } \\
\text { Sarrab et al. (2016) }\end{array}$ \\
\hline Accessibility & $\begin{array}{l}\text { Ability to download files, upload files, easy access to learning } \\
\text { materials and services using } 3 \mathrm{G}, 4 \mathrm{G} \text {, and Wi-Fi. }\end{array}$ & Almaiah et al. (2016) \\
\hline Interface Design & $\begin{array}{l}\text { Ease of use, attractive interface, user satisfaction, attractivity, } \\
\text { learnability, user-friendly, consistency for different platforms. }\end{array}$ & $\begin{array}{l}\text { Almaiah et al. (2016), } \\
\text { Sarrab et al. (2016) }\end{array}$ \\
\hline Interactivity & $\begin{array}{l}\text { Sharing learning content with students and lecturers, discussing and } \\
\text { collaborative learning among learning community. }\end{array}$ & Almaiah et al. (2016) \\
\hline Reliability & $\begin{array}{l}\text { Perform its function and operation without failure; high processing, } \\
\text { performance, and accuracy; robustness, recoverability, and maturity. }\end{array}$ & $\begin{array}{l}\text { Sarrab et al. } \\
(2016)\end{array}$ \\
\hline Availability & Provide learning content and services anytime, anywhere. & Almaiah et al. (2016) \\
\hline Trust & Safe transaction, trust services, security features. & $\begin{array}{l}\text { Al-Mushasha and } \\
\text { Hassan (2009), } \\
\text { Almaiah et al. (2016) }\end{array}$ \\
\hline Responsiveness & $\begin{array}{l}\text { Immediate response, assist users all the time, prompt services, reduce } \\
\text { loading. }\end{array}$ & $\begin{array}{l}\text { Almaiah et al. (2016), } \\
\text { Sarrab et al. (2016) }\end{array}$ \\
\hline Personalization & Control learning, personalized message, record performance. & Almaiah et al. (2016) \\
\hline
\end{tabular}

\section{DATA ANALYSIS RESULTS}

The data analysis method for this research consists of two steps. Step one was conducted using descriptive analysis to find the mean, standard deviation and reliability for all items using SPPS 16. Step two utilizing data mining techniques applied on WEKA.

\section{Descriptive Analysis}

Table (2) represents participants' demographic data, including their gender, age, subject, kinds of mobile devices, and usability of m-learning. Table (3) shows the mean, standard deviation, and Cronbach's alpha for all attributes. Cronbach's alpha test was conducted to check the reliability of the measured data. The coefficients ranged between 0.70 and 0.80 , indicating acceptability (De Vellis, 2003; Sekaran, 2003).

\section{Applied Techniques}

Step two of Data Analysis was performed using data mining techniques applied on WEKA. Three data mining techniques provided by WEKA were used to analyze the data, as they are most suitable for our case: clustering, classification and association Rules. Clustering algorithms are simple K-means and expectation-maximization (EM). The classification algorithm utilized multilayer perceptron (MLP) while the association rules generate a set of rules using the Apriori algorithm. 


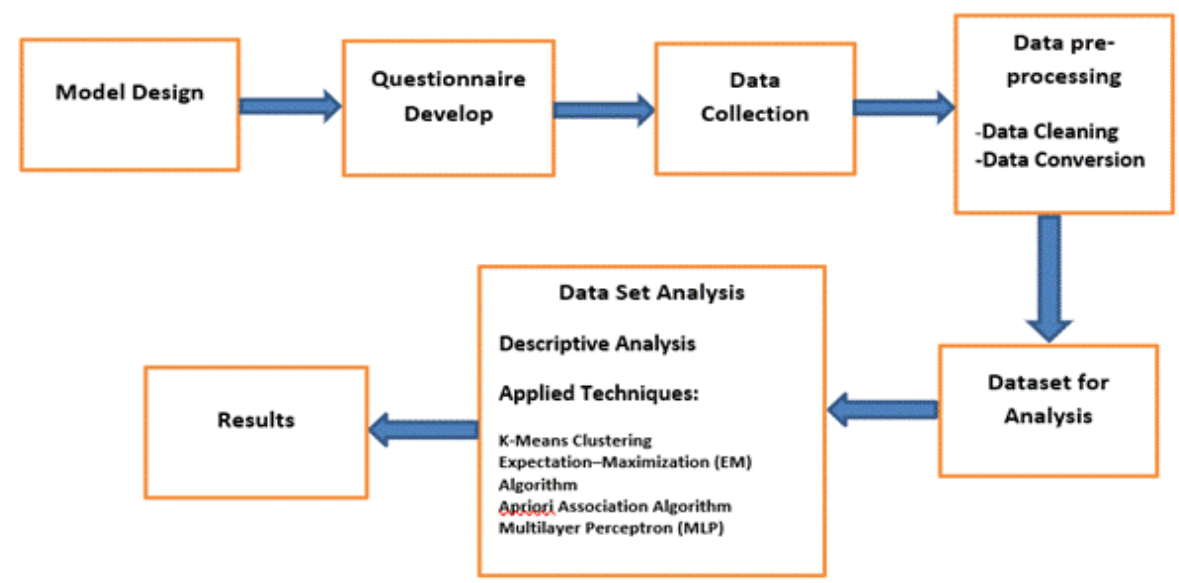

Clustering is an unsupervised learning technique which provides the ability of grouping data in order to find the frequent patterns from our dataset. With clustering there are no class attributes in the data. Clustering thus helps us determining the class attributes from our dataset.

To compare the performance of the EM and K-means algorithms, our data were analyzed using the experimental clustering for all attributes. To compare the performance of K-means and EM, the same data were applied using the WEKA machine learning program.

\section{Experimental Setup}

This research conducted preliminary experiments to determine the suitable configuration of the classification and clustering methods for a proper data analysis. At first, it is implemented with its default parameter settings. Then, its parameter values are carefully tuned to obtain the desired results. Using Weka version 3.6, experiments are conducted on a Windows 10 machine with Core i5 processor and 4 GB of RAM. Table 4 shows the parameter settings for the K-means, EM, Apriori and MLP.

\section{K-Means Clustering}

The K-means clustering algorithm is effective, simple and easy to implement. Also, it is easy to interpret the clustering results. It can be considered as fast and efficient algorithm in terms of computational cost. Table 5 shows the outcomes of the simple K-means clustering algorithm applied to our dataset.

Based on Table 5, all the 151 items are clustered into 5 different clusters using a simple K-means clustering algorithm. The table tells us how each cluster comes together, with a "1" meaning everyone in that cluster shares the same value of one, and a " 0 " meaning everyone in that cluster has a value of zero for that attribute. Numbers are the average value of instances in the cluster. Each cluster shows us a type of preferences for the students, from which the following conclusions are drawn:

- Cluster 0 (18\% of instances): this group comprises 23 year-old male Mathematics students using Samsung mobile devices. They mostly strongly agree with all services provided in m-learning, except they are neutral concerning the trust and availability of services. 
Table 2. Participants' characteristics

\begin{tabular}{|c|c|c|c|}
\hline Characteristic & Frequency & Percent & Cumulative percent \\
\hline \multicolumn{4}{|c|}{ Gender } \\
\hline Female & 69 & 45.7 & 45.7 \\
\hline Male & 82 & 54.3 & 100 \\
\hline \multicolumn{4}{|c|}{ Age } \\
\hline $19-21$ & 56 & 37.1 & 37.1 \\
\hline $22-25$ & 78 & 51.6 & 88.7 \\
\hline Over 25 & 17 & 11.3 & 100 \\
\hline \multicolumn{4}{|c|}{ Subject } \\
\hline CIS & 18 & 11.9 & 11.9 \\
\hline Civil Engineering & 17 & 11.3 & 23.2 \\
\hline $\mathrm{CS}$ & 75 & 49.7 & 72.8 \\
\hline Math & 9 & 6.0 & 78.8 \\
\hline Computer Network & 32 & 21.2 & 100 \\
\hline \multicolumn{4}{|c|}{ Mobile device } \\
\hline Huawei & 66 & 43.7 & 43.7 \\
\hline iPhone & 41 & 27.2 & 70.9 \\
\hline Nokia & 2 & 1.3 & 72.2 \\
\hline Samsung & 3 & 25.2 & 97.4 \\
\hline Sony & 4 & 2.6 & 100 \\
\hline \multicolumn{4}{|c|}{ Use of m-learning } \\
\hline Yes & 144 & 95.4 & 95.4 \\
\hline No & 7 & 4.6 & 100 \\
\hline \multicolumn{4}{|c|}{ Internet plan } \\
\hline Yes & 142 & 94.0 & 94.0 \\
\hline No & 9 & 6.0 & 100 \\
\hline \multicolumn{4}{|c|}{ Years of using m-learning } \\
\hline Less than 1 year & 15 & 9.9 & 9.9 \\
\hline $1-3$ years & 45 & 29.8 & 39.7 \\
\hline $3-5$ years & 91 & 60.3 & 100 \\
\hline & & & \\
\hline & & & \\
\hline
\end{tabular}

- Cluster 1 (32\%): this group comprises 23 year-old female Computer Science students who use Huawei mobile devices. They mostly strongly agree with all services provided in m-learning.

- Cluster 2 (19\%): this group comprises 21 year-old female students of Computer Science who use iPhone mobile devices. They mostly strongly agree with all services provided in m-learning.

- Cluster $3(13 \%)$ : this group is relatively small, and it is not statistically relevant nor significantly affecting the analysis, but it can be useful in supporting some factors (e.g. personalization and 
Table 3. Mean, standard deviation, and Cronbach's alpha for all attributes

\begin{tabular}{|c|c|c|c|c|}
\hline Factors & Items & Mean & $\begin{array}{c}\text { Std } \\
\text { Deviation }\end{array}$ & $\begin{array}{c}\text { Cronbach's } \\
\text { Alpha }\end{array}$ \\
\hline & CU1 & 4.2583 & 0.82027 & 0.764 \\
\hline \multirow[t]{3}{*}{ Contents Usefulness } & CU2 & 4.4437 & 0.77140 & \\
\hline & CU3 & 4.4967 & 0.72915 & \\
\hline & CU4 & 4.3841 & 0.80714 & \\
\hline \multirow[t]{2}{*}{ Scalability } & $\mathrm{SC} 1$ & 4.2185 & 0.82376 & 0.701 \\
\hline & $\mathrm{SC} 2$ & 4.2649 & 0.85403 & \\
\hline \multirow[t]{3}{*}{ Security } & SE1 & 4.5364 & 0.75520 & 0.761 \\
\hline & SE2 & 4.5033 & 0.72915 & \\
\hline & SE3 & 4.3377 & 0.76496 & \\
\hline \multirow[t]{3}{*}{ Functionality } & $\underline{F U 1}$ & 4.2119 & 0.87643 & 0.721 \\
\hline & FU2 & 4.0331 & 0.90493 & \\
\hline & FU3 & 4.2318 & 0.83621 & \\
\hline \multirow[t]{3}{*}{ Accessibility } & $\mathrm{ACC} 1$ & 4.2848 & 0.85928 & 0.712 \\
\hline & $\mathrm{ACC} 2$ & 4.2450 & 0.75690 & \\
\hline & ACC3 & 4.3576 & 0.84336 & \\
\hline \multirow[t]{3}{*}{ Interface Design } & Inerface 1 & 4.2517 & 0.73229 & 0.702 \\
\hline & Interface2 & 4.2781 & 0.74975 & \\
\hline & Interface 3 & 4.4238 & 0.78687 & \\
\hline \multirow[t]{2}{*}{ Interactivity } & Interactivity 1 & 4.2781 & 0.80960 & 0.726 \\
\hline & Iinteractivity 2 & 4.3841 & 0.80714 & \\
\hline \multirow[t]{2}{*}{ Reliability } & RE1 & 4.4503 & 0.75444 & 0.713 \\
\hline & RE2 & 4.5033 & 0.68190 & \\
\hline \multirow[t]{2}{*}{ Availability } & AV1 & 4.2119 & 0.92815 & 0.710 \\
\hline & AV2 & 4.2384 & 0.87718 & \\
\hline \multirow[t]{3}{*}{ Trust } & TR1 & 4.3709 & 0.81335 & 0.755 \\
\hline & TR2 & 4.3510 & 0.74116 & \\
\hline & TR3 & 4.3311 & 0.82237 & \\
\hline Responsiveness & RESP1 & 4.3841 & 0.79884 & 0.723 \\
\hline
\end{tabular}


Table 3. Continued

\begin{tabular}{|l|c|c|c|c|}
\hline Factors & Items & Mean & $\begin{array}{c}\text { Std } \\
\text { Deviation }\end{array}$ & $\begin{array}{c}\text { Cronbach's } \\
\text { Alpha }\end{array}$ \\
\hline & RESP2 & 4.2781 & 0.76732 & \\
\hline & RESP3 & 4.3377 & 0.72927 & \\
\hline \multicolumn{5}{|l|}{} \\
\hline Personalization & PERS1 & 4.3311 & 0.78928 & 0.734 \\
\hline & PERS2 & 4.2583 & 0.84430 & \\
\hline
\end{tabular}

Table 4. Experimental setup for K-means, EM, Apriori and MLP

\begin{tabular}{|c|c|c|}
\hline Algorithm & Parameter & Value \\
\hline \multirow[t]{5}{*}{ K-means } & Distance function & Euclidean distance \\
\hline & Initialization method & Random \\
\hline & Number of clusters & 5 \\
\hline & Seed number & 10 \\
\hline & Cluster mode & percentage split $66 \%$ \\
\hline \multirow[t]{4}{*}{ EM } & Initialization method & Random \\
\hline & Number of clusters & 5 \\
\hline & Seed number & 100 \\
\hline & Cluster mode & 10 folds cross-validation \\
\hline \multirow[t]{4}{*}{ Apriori } & Delta $=0.05$ & 0.05 \\
\hline & Metric $=$ confidence & Confidence \\
\hline & Minimum metric & .9 \\
\hline & Number of rules & 10 \\
\hline \multirow[t]{5}{*}{ MLP } & Hidden layers & $\begin{array}{l}\text { number of attributes + number of } \\
\text { classes }\end{array}$ \\
\hline & Learning rate & .03 \\
\hline & Momentum & .02 \\
\hline & Epoch & 100 \\
\hline & Test mode & percentage split $66 \%$ \\
\hline
\end{tabular}


responsiveness) considered by other groups. This group comprises 20 year-old male students of Computer Science who use Huawei mobile devices. They are mainly disappointed or neutral with the services provided by the m-learning.

- Cluster 4 (19\%): this group comprises 27 year-old Male Computer Network students who use Samsung mobile devices. Even though they are 27 years old and used m-learning for less than a year, they are greatly satisfied with all services provided via m-learning and totally agree with it.

\section{Expectation-Maximization (EM) Algorithm}

Table 6 (Appendix 2) shows the results of EM clustering algorithm experimental applied to our dataset. Table 6 shows relatively similar results to the ones in Table 5, but with less quality. However, results obtained by the EM clustering algorithm are more detailed with respect to the mean errors of correct clustering. It provides the mean and standard deviations for each attribute value in each cluster.

Results obtained by K-means clustering algorithm used the same conditions as were set for the EM clustering algorithm. The results showed that the processing speed of the K-means clustering $(0.01$ seconds) is faster than that with the EM clustering (0.06 seconds). K-means performed 5 iterations, while the EM clustering performed 3. K-means showed a sum of squared errors within clusters about 47.8, while the EM showed a log likelihood of -30.19 . Considering attributes values in the Tables (1) and (2), K-means showed the percentage of respondents who belonged to their cluster based on their answers (data types or scales), while the EM clustering showed the mean and standard deviation values for each attribute.

The classification accuracy of the data is $99 \%$ for the K-means, $100 \%$ accuracy was obtained by the EM. In order to simplify the results, Figure (2) visualizes the clusters obtained by the K-means clustering algorithm.

Taking one example from all instances, Using Mobile Learning versus Content Usefulness, it can be seen from Figure (3) that the 5 clusters are grouped for the values of the two attributes (namely: use m-learning as the $\mathrm{X}$ axis and CU1 as the $\mathrm{Y}$ axis), and are mainly concentrated at the top-left corner around the scale number 5 . Which indicates a strongly agree of the provided service in mobile learning. In other words, most students are using mobile learning services due to their satisfaction with the content Usefulness. This represents the students' satisfaction with using m-learning frequently rather than occasionally. This is one example, the rest of the instances show a similar degree of satisfaction, such as: Scalability, Security, Interface Design, and Reliability.

\section{Multilayer Perceptron (MLP)}

The multilayer perceptron (MLP) is a class of feed forward artificial neural network (ANN) which uses a supervised learning technique called back propagation algorithm for training. MLP is utilized for classification tasks. It consists of three layers: input layer, hidden layer, and output layer. Learning is typically based on the minimization of measurement errors between network outputs and desired outputs.

Appling the MLP to our data sets, we found that scalability factor including SC1 and SC2 has a high accuracy of $99.33 \%$ (the highest accuracy rate in comparison with other factors). This result revealed that the scalability factor of $\mathrm{m}$-learning application affects student satisfaction with m-learning application services. Table 6 shows the results obtained from multilayer perceptron algorithm.

\section{Confusion Matrix}

a b classified as

$0 \quad 139$ a=yes

$111 \mathrm{~b}=$ no 
Table 5. K-means clustering algorithm experimental results (final cluster centroids) *

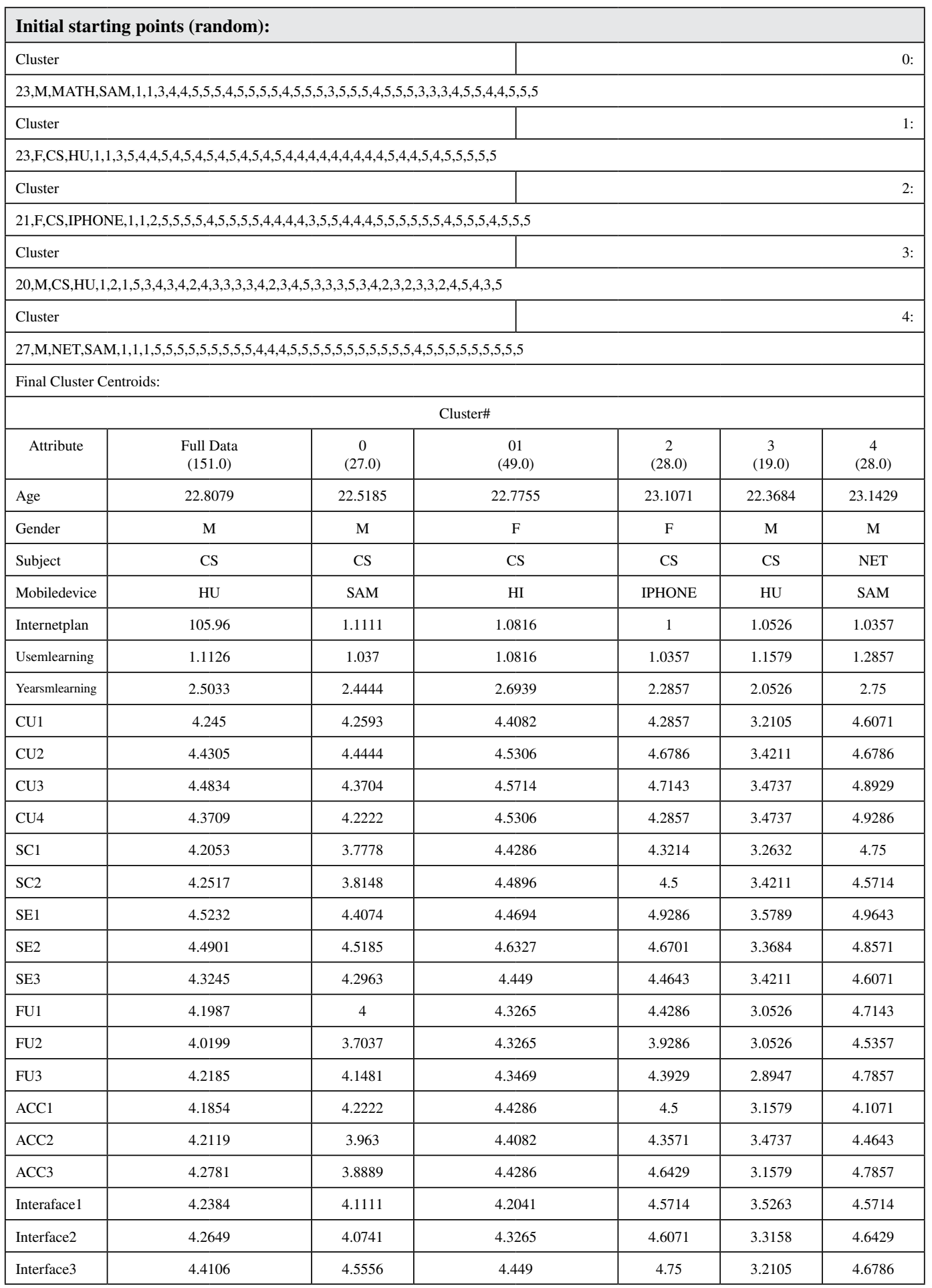




\section{Table 5. Continued}

\begin{tabular}{|c|c|c|c|c|c|c|}
\hline \multicolumn{7}{|c|}{ Initial starting points (random): } \\
\hline Interactivity 1 & 4.2649 & 4.1111 & 4.3061 & 4.5714 & 3.3158 & 4.6786 \\
\hline Interactivity 2 & 4.3709 & 4.4444 & 4.5102 & 4.4286 & 3.0526 & 4.8929 \\
\hline RE1 & 4.4371 & 4.2593 & 4.6735 & 4.75 & 3.0526 & 4.8214 \\
\hline RE2 & 4.4768 & 4.4815 & 4.4694 & 4.7143 & 3.4737 & 4.9286 \\
\hline AV1 & 4.2252 & 4.1852 & 4.3061 & 4.6071 & 3.2105 & 4.4286 \\
\hline AV2 & 4.2384 & 3.8519 & 4.449 & 4.5357 & 3.2632 & 4.6071 \\
\hline TR1 & 4.3709 & 4.1481 & 4.551 & 4.6071 & 3.0526 & 4.9286 \\
\hline TR2 & 4.3377 & 4.1481 & 4.5306 & 4.4286 & 3.4211 & 4.7143 \\
\hline TR3 & 4.3311 & 4.1111 & 4.5714 & 4.4643 & 3.2105 & 4.75 \\
\hline RESP1 & 4.3841 & 4.2963 & 4.5714 & 4.4643 & 3.2632 & 4.8214 \\
\hline RESP2 & 4.2781 & 3.9259 & 4.3878 & 4.5 & 3.5263 & 4.7143 \\
\hline RESP3 & 4.3377 & 4.037 & 4.2857 & 4.5714 & 3.7895 & 4.8571 \\
\hline PERS1 & 4.3311 & 4 & 4.551 & 4.4286 & 3.4737 & 4.75 \\
\hline PERS2 & 4.2583 & 4.0741 & 4.4898 & 4.25 & 3.3684 & 4.6429 \\
\hline PERS3 & 4.3377 & 3.963 & 4.4694 & 4.5 & 3.7368 & 4.7143 \\
\hline \multicolumn{7}{|c|}{ Cluttered Instances } \\
\hline 0 & \multicolumn{6}{|c|}{$27(18 \%)$} \\
\hline 1 & \multicolumn{6}{|c|}{$49(32 \%)$} \\
\hline 2 & \multicolumn{6}{|c|}{$28(19 \%)$} \\
\hline 3 & \multicolumn{6}{|c|}{$19(13 \%)$} \\
\hline 4 & \multicolumn{6}{|c|}{$28(19 \%)$} \\
\hline
\end{tabular}

Figure 3. A visualization of results obtained by the K-means clustering algorithm for 2 instances

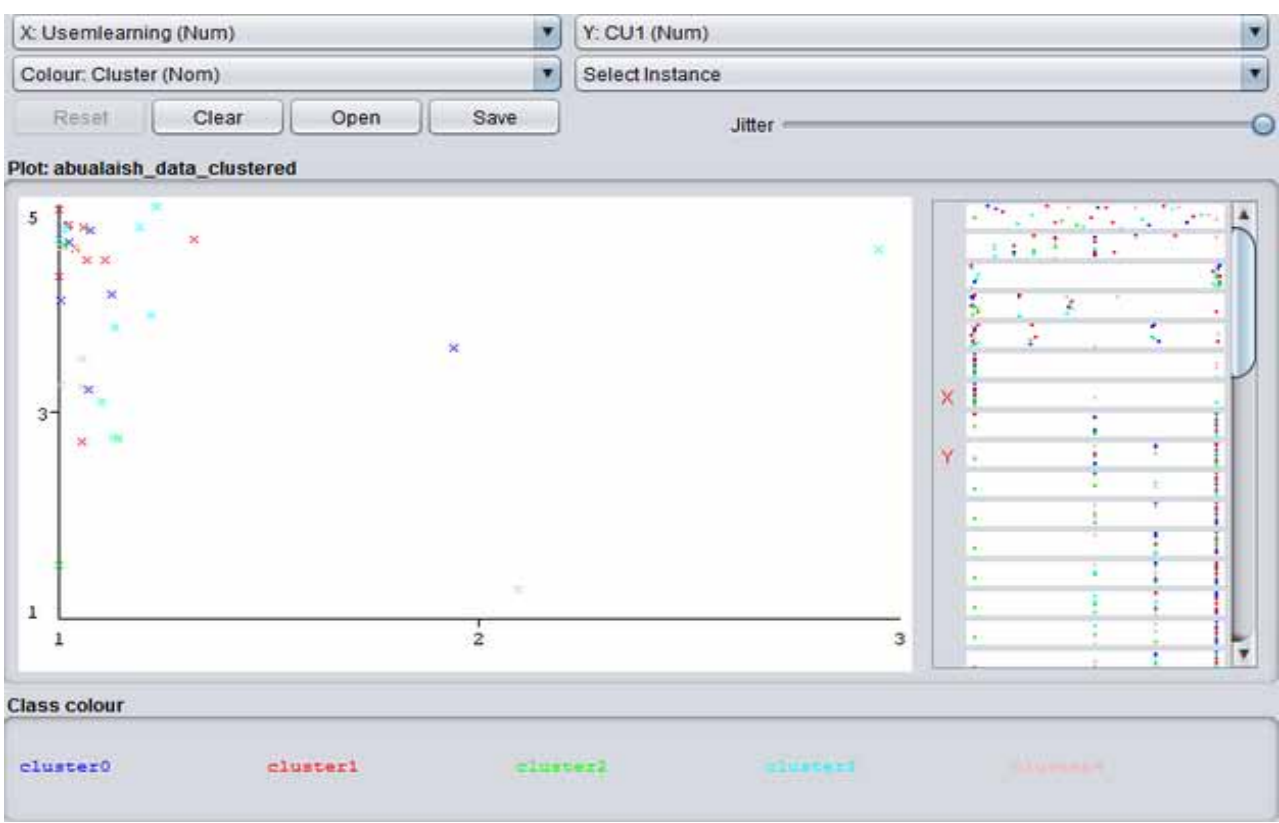




\section{Apriori Association Algorithm}

The Apriori association algorithm is implemented for a more detailed relationship between instances. For example, it identifies the instances (services) that affect student satisfaction with mobile learning. Three sets of rules are produced, with a minimum support of 55\% of the instances, and confidence greater than $90 \%$. These rulesets are 15 items, 18 items, and 3 items.

The best rules found are:

1. Interface $3=588==>$ Use m-learning $=187$

[5] conv:(3.5)

2. Use m-learning $=1 \mathrm{SE} 1=596==>$ internet plan $=194$ [3] conv:(1.91)

3. Use $\mathrm{ml}$ earning $=1 \mathrm{SE} 2=591==>$ internet plan $=189$ [3] conv:(1.81)

4. $\mathrm{SE} 1=5102==>$ internet plan $=199$

[3] conv:(1.52)

5. SE2 $=595==>$ internet plan $=192$

[2] conv:(1.42)

6. internet plan $=1 \mathrm{SE} 2=592==>$ Use m-learning $=189$ [4] conv:(1.83)

7. $\mathrm{SE} 2=595==>$ Use m-learning $=191$

[3] conv:(1.51)

8. $\mathrm{CU} 2=589==>$ Use m-learning $=185$

[3] conv:(1.41)

9. Use m-learning $=1139==>$ internet plan $=1132$ [1] conv:(1.04)

10. internet plan $=1 \mathrm{SE} 1=599==>$ Use m-learning $=194$ [2] conv:(1.31)

$$
\begin{aligned}
& \text { <conf:(0.99)> lift:(1.07) lev:(0.04) } \\
& \text { <conf:(0.98)> lift:(1.04) lev:(0.02) } \\
& \text { <conf:(0.98)> lift:(1.04) lev:(0.02) } \\
& \text { <conf:(0.97)> lift:(1.03) lev:(0.02) } \\
& \text { <conf:(0.97)> lift:(1.03) lev:(0.02) } \\
& \text { <conf:(0.97)> lift:(1.05) lev:(0.03) } \\
& \text { <conf:(0.96)> lift:(1.04) lev:(0.02) } \\
& \text { <conf:(0.96)> lift:(1.04) lev:(0.02) } \\
& \text { <conf:(0.95)> lift:(1.01) lev:(0.01) } \\
& \text { <conf:(0.95)> lift:(1.03) lev:(0.02) }
\end{aligned}
$$

It can be seen that, for example rule number 10, 94 students are willing to use m-learning if they have an internet plan and are totally satisfied with the security service. The factor Use m-learning showed a significant level of importance for 139 students in rule number 9 . In nine rules, using mobile learning (Use m-learning) is totally dependent on the Security service, and in one rule the Content Quality plays a role in using mobile learning. It is worth mentioning that the security factor has been heavily considered by students (95 strongly agreed students), which is presented in rules number 4 , 5 , and 7 as a major independent factor, especially the SE2 factor (privacy and confidentiality), which appeared in 2 rules with a high confidence of $97 \%$. SE1 and SE2 factors were presented in rules 2, 3,6 , and 10 as dependent factors upon the internet plan and Use m-learning factors. In addition, the factor SE1 factor appearing in rule number 4 has the majority of students (102 students out of 151) preferring secure credentials over others. Overall, it can be concluded that the factors SE1 and SE2 have the greatest impact on satisfying students' needs in using m-learning (Use m-learning).

\section{DISCUSSION}

This study has presented a data mining technique to investigate the quality factors of m-learning applications services that support learning and teaching in higher education institutes. The researcher proposed a quality factors model that aims to blending all technical aspects of m-learning services that might affect student's satisfaction with m-learning services. The first part of data analysis was conducted using descriptive statistics. The results revealed that all factors suggested by the proposed model have positive affect on student's satisfaction with m-learning applications services. Table 3 
Table 6. Multilayer perceptron algorithms results

\begin{tabular}{|l|l|l|l|l|l|l|l|l|}
\hline \multicolumn{1}{|c|}{ Detailed Accuracy by class } \\
\hline Weighted Avg & TP Rate & FP Rate & Precision & Recall & F-measure & MCC & Roc Area & PRC \\
\cline { 2 - 10 } & 0.992 & 0.954 & 0.954 & 0.991 & 1.000 & 0.993 & 0.083 & 1.000 \\
\cline { 2 - 10 } & 0.926 & 0.943 & 0.954 & 0.957 & 0.917 & 1.000 & 0.000 & 0.917 \\
\cline { 2 - 10 } & 0.987 & 0.943 & 0.954 & 0.993 & 0.993 & 0.993 & 0.077 & 0.993 \\
\hline
\end{tabular}

shows that all questionnaire items have a mean ranged between 4.03 and 4.53 which falls between 'agree' and 'strongly agree' and indicated that the participants had agreed thoughts regarding to the model factors. This result similar with results obtained by previous researches (Almaiah et al. (2016); Sarrab et al. (2106)).

The second part of data analysis was conducted using data mining techniques applied on WEKA. In first step the researcher performed analysis with two clustering techniques/algorithms, namely k-mean and EM (Dey et al., 2019) in order to identify groups of items that may have a significant impact on the satisfaction of students in using or relying on mobile technology as an assistant tool for learning. Both algorithms indicated the importance of the "Security" factor as a critical component in designing a successful / preferred m-learning application. Both algorithms were implemented to support each other in their indication of some factor of interest. Upon our preliminary experiments, one clustering algorithm was not enough to determine a significant factor (e.g. K-means) with $99 \%$ accuracy. Therefore, another clustering algorithm (e.g. EM) was implemented to support the grouping generated by k-means. It is clearly that EM has obtained a higher accuracy (100\%) than the K-means. Hence, proceeding with the generated grouping (security factor) to the next data mining technique.

Then, the second step, a classification algorithm (namely, MLP) was implemented to predict a descriptive model of the grouping generated by the clustering algorithms in first step. However, this classification step has further indicated the significance of the "scalability" factor with a high F-measure (0.91) and a high (0.99) model accuracy. So, two significant factors are now considered for the third step. In the third step, the association rules algorithm (Apriori) was employed to predict a set of rules driven from the classification or rather the description (generated in step two) of the grouped factors from step one. Apriori has generated 10 sequences of rules that again support the significance of the "security" factor. Consecutively, these 3 steps recommended potential design components for learners based on the predefined factors. The employed algorithms in this proposed model are not to compete for accuracy; they are employed sequentially in order to come out with the best recommendation.

Since it is well known that data mining techniques are capable of discovering patterns and groups of potential data, such as students/learners' preferences or design factors that impact a successful development of m-learning applications. This study highlights model for applying data mining in m-learning to determine its potential.

Based on that, it is required to link learners' preferences and the design components of a preferable development of m-learning applications. Hence, using data mining views a multidimensional perspective. This might lead to a better decision such as, what is the best configuration of designing a successful m-learning application, what are the critical components/requirements that hinder/support the success of m-learning applications, or even that hinder/support learners interacting effectively with the application. In general, data mining techniques are to discover patterns/factors that have the potential to become an actual application.

The research results focusing on security and scalability factors because they have highest impact on student's satisfaction with m-learning services. Students need m-learning applications that keep user's data confidentially and privacy. Also, has ability to accommodate changes made to the 
application and ability to handle multiple types of contents and large number of users (Sarrab et al., 2016). In addition, the factors that suggestions by the proposed model will enhance the implementation of mobile learning through improving learning performance and learning contexts (Garcia-Cabot et al., 2015).

\section{Contribution and Benefit of Research Outcomes}

There is a lake of researches that investigated the technical aspects of m-learning applications services. This research added value to the previous literature in mobile learning applications services through designing a model of technical quality factors that enhanced this technology in universities teaching and learning methods. The results indicate that students consider security and scalability are the most important services that should m-learning applications provide. This result gives an important insight for people who designing and developing m-learning applications.

Security should be considered while designing m-learning applications; m-learning applications have to protect data and implement control over authentication, authorization and sharing contents. Students worried about losing confidential information, stop having privacy, change of learning quality and authorized users' access learning contents. Lecturers also concerned about control over e-examinations. Therefore m-learning designers should integrate some security technologies in m-learning applications. This includes access control mechanisms, firewalls, anti-viruses, digital identity to each users, authentication and authorization.

Furthermore, scalability is other factor that needs to be integrated with m-learning applications. M-learning applications should have ability to handle and manage a large number of data and allowed a large number of users to access applications from different locations at the same time. M-learning applications need to be refined and extended in order to outfit different needs and complex issues. In addition, m-learning applications should have a suitable graphical user interface that can be modified to integrate newly features.

\section{CONCLUSION}

Overall, the results of this research reveal that all of the quality factors have a positive effect on student satisfaction with m-learning application services. Furthermore, these factors meet students' needs and requirements to implement this tool within the learning process. Security and scalability factors were discovered to be a quality aspect that has the highest impact on student satisfaction with m-learning application services. The classification accuracy of the data is $99 \%$ for the K-means, while $100 \%$ accuracy was obtained by the EM for the "security" factor, and $99.33 \%$ accuracy was achieved by the MLP for the "scalability" factor.

This research provides empirical support for discovering the guidelines and instructions to design and develop high-quality m-learning applications. Designers should consider all technical factors in the proposed model with more attention to security and scalability factors while designing and developing m-learning applications.

This study is limited to university students more researches for universities lecturers are highly needed to evaluate the model proposed. Also, there is a difficulty to compare the study results with similar research due to the lake of researches in technical aspect of m-learning quality services that utilized same data mining techniques. Furthermore, the data analysis of this study limited to some technical data mining algorithms, Next researches should use other algorithms with high performance. Future work might aim to investigate the feasibility of model components on different mobile learning applications, and additional work is needed to integrate more nontechnical factors in the model, including teaching pedagogy, learning approach, and management support. 


\section{REFERENCES}

Abu-Al-Aish, A., \& Love, S. (2013). Factors influencing students' acceptance of M-learning: An investigation in higher education. International Review of Research in Open and Distance Learning, 14(5), 82-107. doi:10.19173/ irrodl.v14i5.1631

Al-Mushasha, N., \& Shahizan, H. (2009). A model for mobile learning service quality in university environment. International Journal of Mobile Computing and Multimedia Communications, 1(1), 70-91. doi:10.4018/ jmcmc.2009010105

Ali, A., Ouda, A., \& Capretz, L. F. (2012). A Conceptual Framework for Measuring the Quality Aspects of Mobile Learning. Bulletin of the IEEE Technical Committee on Learning Technology, 14(4), 31-34.

Almaiah, M.A., Jalil, M.A. \& Man, M. (2016). Empirical investigation to explore factors that achieve high quality of mobile learning system based on students' perspectives. Engineering Science and Technology, an International Journal, 19(3), 1314-1320.

Almarashdeh, I. A., Sahari, N., Zin, N. A. M., \& Alsmadi, M. (2010). The success of learning management system among distance learners in Malaysian Universities. Journal of Theoretical and Applied Information Technology, 21(2), 80-91.

Alnabhan, M., Abu-Al-Aish, A., \& Al-Masaeed, S. A. (2018). Collaborative and ubiquitous mobile learning system prototype. International Journal of Computer Applications in Technology, 58(4), 296-307. doi:10.1504/ IJCAT.2018.095939

Benhamida, V., Bouallouche-Medjkoune, L., Ai“ssani, D., \& Lafifi, Y. (2017). Improving the Quality of Mobile Learning Services. Wireless Personal Communications, 97(4), 5305-5324. doi:10.1007/s11277-017-4780-4

De Vellis, R. F. (2003). Scale Development: Theory and Applications. Sage Publications.

DeLone, W. H., \& McLean, E. R. (2003). The DeLone and McLean model of information systems success:A tenyear update. Journal of Management Information Systems, 19(4), 9-30. doi:10.1080/07421222.2003.11045748

Dey, N., Wagh, S., Mahalle, P. N., \& Pathan, M. S. (Eds.). (2019). Applied machine learning for smart data analysis. CRC Press. doi:10.1201/9780429440953

Drigas, A. S., \& Pappas, M. A. (2015). A Review of Mobile Learning Applications for Mathematics. International Journal of Interactive Mobile Technologies, 9(3), 18-23. doi:10.3991/ijim.v9i3.4420

Garcia-Cabot, A., de-Marcos, L., \& Garcia-Lopez, E. (2015). An empirical study on m-learning adaptation: Learning performance and learning contexts. Computers \& Education, 82, 450-459. doi:10.1016/j. compedu.2014.12.007

Giannakoulas, A., \& Xinogalos, S. (2018). A pilot study on the effectiveness and acceptance of an educational game for teaching programming concepts to primary school students. Education and Information Technologies, 23(5), 2029-2052. doi:10.1007/s10639-018-9702-x

Glood, S. H., \& Hussein, R. M., \& Abduladheem, W. (2018). The Effects of Information Quality, Service Quality, And Combatability On Continue Use of m-learning Among Students in the Public Universities of Iraqi. Journal of Theoretical and Applied Information Technology, 96(12), 3739-3755.

Guo, S. H. M., Chong, P. P., \& Chang, H. K. (2007). Mobile learning in nursing practical learning: An applicability analysis. International Journal of Mobile Learning and Organization, 1(4), 342-354. doi:10.1504/ IJMLO.2007.016175

Hsu, T.-Y., Chiou, C.-K., Tseng, J., \& Hwang, G.-J. (2016). Development and evaluation of an active learning support system for context-aware ubiquitous learning. IEEE Transactions on Learning Technologies, 9(1), 37-45. doi:10.1109/TLT.2015.2439683

Huang, C. S. J., Yang, S. J. H., Chiang, T. H. C., \& Su, A. Y. S. (2016). Effects of Situated Mobile Learning Approach on Learning Motivation and Performance of EFL Students. Journal of Educational Technology \& Society, 19(1), 263-276. 
Hung, P. H., Hwang, G. J., Lee, Y. H., Wu, T. H., Vogel, B., Milrad, M., \& Johansson, E. (2014). A problem-based ubiquitous learning approach to improving the questioning abilities of elementary school students'. Journal of Educational Technology \& Society, 17(4), 316-334.

John, S., \& Rani, M. S. (2015). Teaching java programming on smartphone-pedagogy and innovation; proposal of its ontology oriented implementation. Procedia: Social and Behavioral Sciences, 176, 787-794. doi:10.1016/j. sbspro.2015.01.541

Jones, A., Issroff, K., Scanlon, E., Clough, G., McAndrew, P., \& Blake, C. (2006). Using mobile devices for learning in informal settings: is it motivating? In Proceedings of IADIS International Conference on Mobile Learning. IADIS Press.

Kim, G. M., \& Ong, S. M. (2005). An exploratory study of factors influencing m-learning success. Journal of Computer Information Systems, 46(1), 92-97.

Liu, Y., Li, H., \& Carlsson, C. (2010). Factors driving the adoption of m-learning: An empirical study. Computers \& Education, 55(3), 1211-1219. doi:10.1016/j.compedu.2010.05.018

Motiwalla, L. F. (2007). Mobile learning: A framework and evaluation. Computer Education, 49(3), 581-596. doi:10.1016/j.compedu.2005.10.011

Oyelere, S. S., \& Suhonen, J. (2016). Design and implementation of MobileEdu m-learning application for computing education in Nigeria: A design research approach. Proceedings of Fourth International Conference on Learning and Teaching in Computing and Engineering, 27-31. doi:10.1109/LaTiCE.2016.3

Oyelere, S. S., Suhonen, J., Wajiga, G. M., \& Sutinen, E. (2018). Design, development, and evaluation of a mobile learning application for computing education. Education and Information Technologies, 23(1), 467-495. doi:10.1007/s10639-017-9613-2

Sarrab, M., Alalwan, N., Alfarraj, O., \& Alzahran, A. (2015). An empirical study on cloud computing requirements for better mobile learning services. International Journal of Mobile Learning and Organisation, 9(1), 1-20. doi:10.1504/IJMLO.2015.069709

Sarrab, M., Elbasir, M., \& Alnaeli, S. (2016). Towards a quality model of technical aspects for mobile learning services: An empirical investigation. Computers in Human Behavior, 55, 100-112. doi:10.1016/j.chb.2015.09.003

Sekaran, U. (2003). Research Methods for Business: A Skill-Building Approach. John Wiley \& Sons.

Traxler, J. (2009). Learning in a mobile age. International Journal of Mobile and Blended Learning, 1(1), 1-12. doi:10.4018/jmbl.2009010101

Troussas, C., Virvou, M., \& Alepis, E. (2014). Collaborative learning: Group interaction in an intelligent mobile-assisted multiple language learning system. Informatics in Education, 13(2), 279-292. doi:10.15388/ infedu.2014.17

Venkatesh, V., Morris, M. G., Davis, G. B., \& Davis, F. D. (2003). User acceptance of information technology: Toward a unified view. Management Information Systems Quarterly, 27(3), 425-478. doi:10.2307/30036540

Virtanen, M. A., Elina Haavisto, E., Eeva Liikanen, E., \& Kääriäinen, M. (2018). Ubiquitous learning environments in higher education: A scoping literature review. Education and Information Technologies, 23(2), 985-998. doi:10.1007/s10639-017-9646-6

Wang, H. Y., Liu, G. Z., \& Hwang, G. J. (2016). Integrating sociocultural contexts and location based systems for ubiquitous language learning in museums: A state of the art review of 2009-2014. British Journal of Educational Technology, 48(2), 653-671. doi:10.1111/bjet.12424

Wingkvist, A. (2009). Understanding scalability and sustainability in mobile learning: A systems development framework. Vaxjo University Press.

Wu, P.-H., Hwang, G.-J., Su, L.-H., \& Huang, Y.-M. (2012). A context-aware mobile learning system for supporting cognitive apprenticeships in nursing skills training. Journal of Educational Technology \& Society, 15(1), 223-236. 


\section{APPENDIX 1: QUESTIONNAIRE}

Age: Gender: Subject and level:

1. What kind of mobile device you have:

2. Do you have a mobile internet package plan? 1. Yes 2. No

Explain your connection type and speed

3. Do you use m-learning in your studies? 1. Yes 2. No

4. Years of using m-learning

1. less than 1 year 2. 1-3 years 3. 3-5 years

On a scale of 1 to 5, indicate with an û how strongly you agree or disagree with each of the following statements.

\section{Rating Scale}

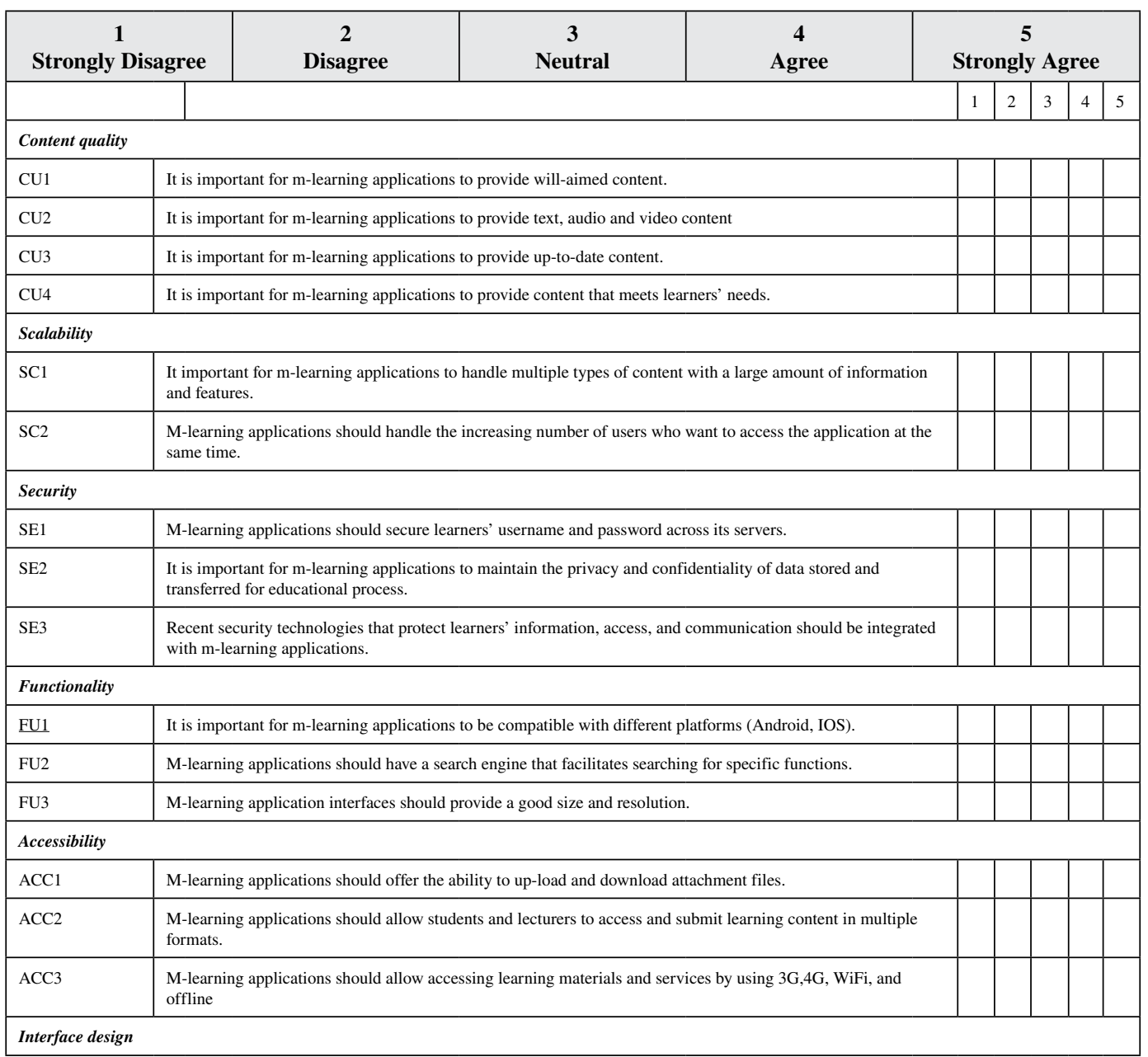




\section{Rating Scale Continued}

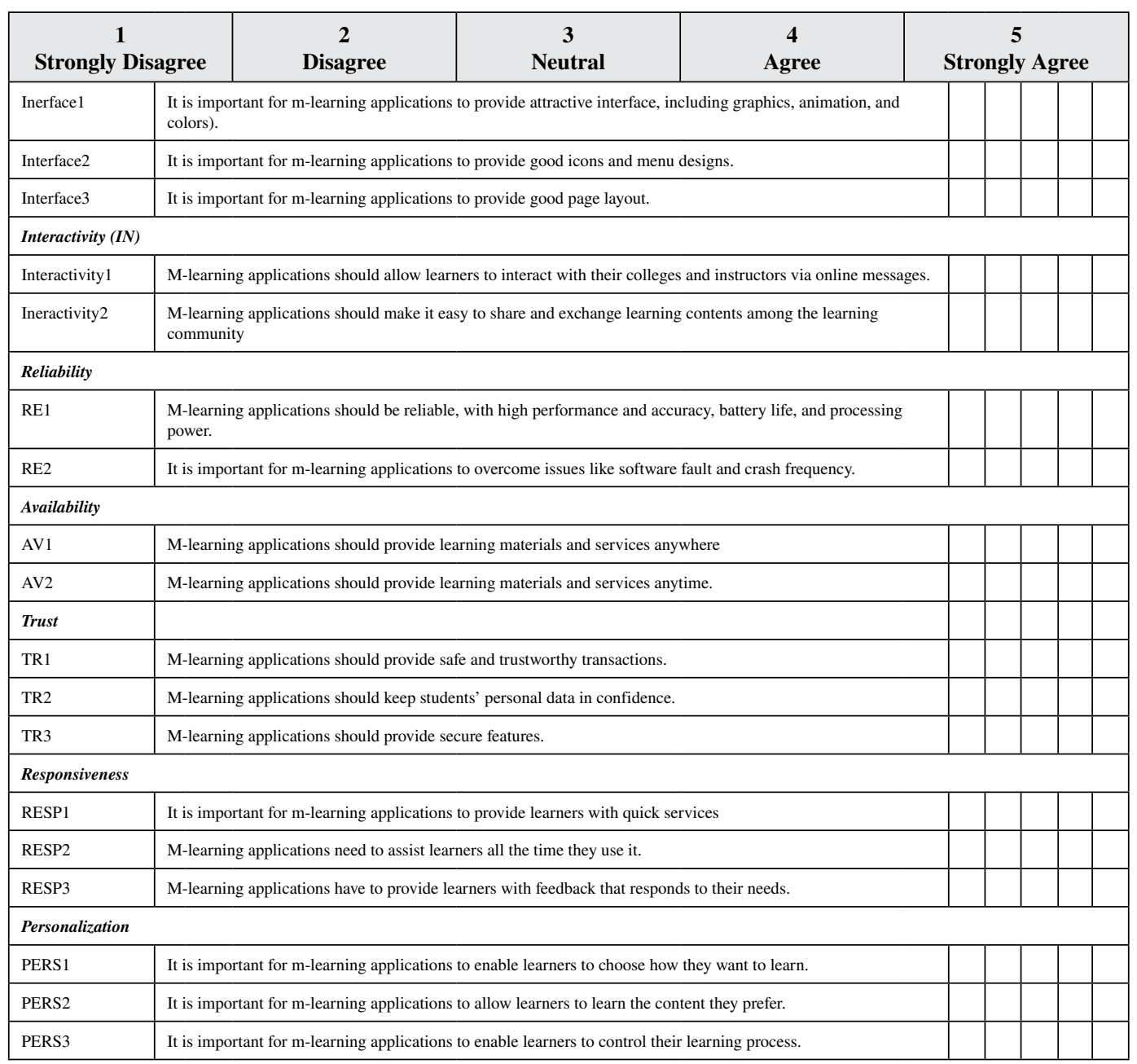




\section{APPENDIX 2:}

\section{Table 7. EM clustering algorithm experimental results}

\begin{tabular}{|c|c|c|c|c|c|}
\hline \multicolumn{6}{|c|}{ Cluster } \\
\hline Attribute & 0 & 1 & 2 & 3 & 4 \\
\hline & $(0.23)$ & $(0.23)$ & $(0.3)$ & $(0.12)$ & $(0.11)$ \\
\hline \multicolumn{6}{|l|}{ Age } \\
\hline Mean & 23.3776 & 24.1333 & 21.2532 & 22.6569 & 23.2455 \\
\hline Std. dev. & 2.9625 & 2.9875 & 1.4057 & 2.8198 & 0.9899 \\
\hline \multicolumn{6}{|l|}{ Gender } \\
\hline $\mathrm{F}$ & 21.2116 & 11 & 32.1599 & 6.0039 & 3.6246 \\
\hline M & 15.6321 & 26.1067 & 15.4194 & 14.7415 & 15.1003 \\
\hline [total] & 36.8436 & 37.1068 & 47.5793 & 20.7454 & 18.7249 \\
\hline \multicolumn{6}{|l|}{ subject } \\
\hline CS & 21.3041 & 17.1068 & 19.1749 & 10.0032 & 12.411 \\
\hline CIVIL & 2.0575 & 9 & 5.0963 & 2.6183 & 3.228 \\
\hline NET & 11.5732 & 7 & 10.4685 & 6.9073 & 1.051 \\
\hline CIS & 1.9304 & 6 & 9.8255 & 3.2167 & 2.0274 \\
\hline MATH & 2.9784 & 1 & 6.014 & 1 & 3.0075 \\
\hline [total] & 39.8436 & 40.1068 & 50.5793 & 23.7454 & 21.7249 \\
\hline \multicolumn{6}{|c|}{ Mobile device } \\
\hline $\mathrm{HU}$ & 6.9478 & 17.1067 & 32.2439 & 12.7426 & 1.959 \\
\hline SAM & 9.941 & 10 & 8.3061 & 2.0002 & 12.7526 \\
\hline SONY & 2.9968 & 1 & 2.9904 & 1 & 1.0128 \\
\hline IPHONE & 18.9581 & 10 & 6.0387 & 7.0026 & 4.0005 \\
\hline NOKIA & 1 & 2 & 1.0001 & 1 & 1.9999 \\
\hline [total] & 39.8436 & 40.1068 & 50.5793 & 23.7454 & 21.7249 \\
\hline \multicolumn{6}{|c|}{ Internet plan } \\
\hline Mean & 1.0861 & 1.2279 & 1.0552 & 1.155 & 1.0347 \\
\hline Std. dev. & 0.0406 & 0 & 0.3308 & 0.2247 & 0.3408 \\
\hline \multicolumn{6}{|c|}{ Use mlearning } \\
\hline mean & 1.0861 & 1.2279 & 1.0552 & 1.155 & 1.0347 \\
\hline Std. dev. & 0.2805 & 0.6355 & 0.2887 & 0.3619 & 0.2607 \\
\hline \multicolumn{6}{|c|}{ Years mlearning } \\
\hline Mean & 2.3761 & 2.9115 & 2.3461 & 2.0647 & 2.8314 \\
\hline Std. dev. & 0.7245 & 0.284 & 0.6657 & 0.7709 & 0.3744 \\
\hline \multicolumn{6}{|l|}{ CU1 } \\
\hline Mean & 4.4957 & 4.7091 & 4.036 & 3.163 & 4.5313 \\
\hline Std. dev. & 0.5494 & 0.5712 & 0.7577 & 1.0582 & 0.586 \\
\hline \multicolumn{6}{|l|}{ CU2 } \\
\hline Mean & 4.678 & 4.7721 & 4.2754 & 3.5529 & 4.6038 \\
\hline
\end{tabular}


Table 7. Continued

\begin{tabular}{|c|c|c|c|c|c|}
\hline \multicolumn{6}{|c|}{ Cluster } \\
\hline Std. dev. & 0.5243 & 0.5384 & 0.7424 & 1.2194 & 0.4891 \\
\hline \multicolumn{6}{|l|}{ CU3 } \\
\hline mean & 4.6571 & 4.94 & 4.3611 & 3.511 & 4.5867 \\
\hline Std. dev. & 0.4749 & 0.2375 & 0.7907 & 0.9896 & 0.602 \\
\hline \multicolumn{6}{|l|}{ CU4 } \\
\hline Mean & 4.4862 & 4.943 & 4.0722 & 3.4132 & 4.8168 \\
\hline Std. dev. & 0.7328 & 0.2318 & 0.7703 & 1.0469 & 0.3869 \\
\hline \multicolumn{6}{|l|}{$\mathrm{SC} 1$} \\
\hline Mean & 4.3934 & 4.7691 & 3.9741 & 3.2315 & 4.3515 \\
\hline Std. dev. & 0.6453 & 0.4214 & 0.8291 & 0.9736 & 0.6842 \\
\hline \multicolumn{6}{|l|}{$\mathrm{SC} 2$} \\
\hline Mean & 4.5898 & 4.6012 & 4.2079 & 3.4882 & 3.7886 \\
\hline Std. dev. & 0.4988 & 0.5947 & 0.9463 & 1.031 & 0.9061 \\
\hline \multicolumn{6}{|l|}{ SE1 } \\
\hline mean & 4.6164 & 5 & 4.4766 & 3.6064 & 4.4825 \\
\hline Std. dev. & 0.643 & 0.7986 & 0.743 & 1.1713 & 0.6098 \\
\hline \multicolumn{6}{|l|}{ SE2 } \\
\hline Mean & 4.5414 & 4.9145 & 4.63 & 3.4462 & 4.2808 \\
\hline Std. dev. & 0.6483 & 0.2796 & 0.4828 & 1.1285 & 0.749 \\
\hline \multicolumn{6}{|l|}{ SE3 } \\
\hline Mean & 4.5902 & 4.6582 & 4.1734 & 3.4463 & 4.4665 \\
\hline Std. dev. & 0.6433 & 0.6292 & 0.6712 & 0.9765 & 0.6988 \\
\hline \multicolumn{6}{|l|}{ FU1 } \\
\hline Mean & 4.5145 & 4.9145 & 3.8435 & 2.8516 & 4.5158 \\
\hline Std. dev. & 0.5547 & 0.2796 & 0.8204 & 0.7593 & 0.6077 \\
\hline \multicolumn{6}{|l|}{ FU2 } \\
\hline Mean & 4.1888 & 4.6297 & 3.9066 & 2.7489 & 4.1212 \\
\hline Std. dev. & 0.9214 & 0.5892 & 0.7103 & 0.9048 & 0.5862 \\
\hline \multicolumn{6}{|l|}{ FU3 } \\
\hline Mean & 4.2287 & 5 & 4.0823 & 3.0613 & 4.2254 \\
\hline Std. dev. & 0.5902 & 0.0004 & 0.645 & 1.1391 & 0.8101 \\
\hline \multicolumn{6}{|l|}{ ACC1 } \\
\hline Mean & 4.4547 & 4.5412 & 4.1107 & 3.2136 & 4.1706 \\
\hline Std. dev. & 1.0279 & 1.0502 & 0.8183 & 0.9565 & 0.8704 \\
\hline \multicolumn{6}{|l|}{$\mathrm{ACC} 2$} \\
\hline Mean & 4.4584 & 4.6297 & 4.0668 & 3.2938 & 4.246 \\
\hline Std. dev. & 0.6025 & 0.795 & 0.7479 & 0.8369 & 0.5321 \\
\hline \multicolumn{6}{|l|}{$\mathrm{ACC} 3$} \\
\hline mean & 4.7677 & 5 & 4.0033 & 3.295 & 3.594 \\
\hline
\end{tabular}


Table 7. Continued

\begin{tabular}{|c|c|c|c|c|c|}
\hline \multicolumn{6}{|c|}{ Cluster } \\
\hline Std. dev. & 0.4224 & 0.9741 & 1.0219 & 0.9773 & 0.9334 \\
\hline \multicolumn{6}{|l|}{ Interface 1} \\
\hline Mean & 4.5691 & 4.5982 & 4.0023 & 3.3686 & 4.4127 \\
\hline Std. dev. & 0.4955 & 0.4903 & 0.7 & 1.0423 & 0.4974 \\
\hline \multicolumn{6}{|l|}{ Interface2 } \\
\hline Mean & 4.5723 & 4.7436 & 3.9995 & 3.455 & 4.2505 \\
\hline Std. dev. & 0.4947 & 0.4976 & 0.7237 & 0.9975 & 0.6382 \\
\hline \multicolumn{6}{|l|}{ Interface 3} \\
\hline Mean & 4.7105 & 4.8006 & 4.2966 & 3.3394 & 4.4783 \\
\hline Std. dev. & 0.4542 & 0.4654 & 0.7478 & 1.165 & 0.6073 \\
\hline \multicolumn{6}{|c|}{ Interactivity1 } \\
\hline mean & 4.4741 & 4.7976 & 4.0838 & 3.3978 & 4.1763 \\
\hline Std. dev. & 0.6152 & 0.4018 & 0.8507 & 1.0259 & 0.7183 \\
\hline \multicolumn{6}{|c|}{ Interactivity2 } \\
\hline Mean & 4.4805 & 5 & 4.3159 & 3.1844 & 4.3014 \\
\hline Std. dev. & 0.6921 & 0 & 0.6626 & 1.1329 & 0.5762 \\
\hline \multicolumn{6}{|l|}{ RE1 } \\
\hline mean & 4.7679 & 4.8006 & 4.4289 & 3.0447 & 4.5676 \\
\hline Std. dev. & 0.4222 & 0.4654 & 0.6584 & 0.6852 & 0.6782 \\
\hline \multicolumn{6}{|l|}{ RE2 } \\
\hline Mean & 4.766 & 4.883 & 4.3409 & 3.5466 & 4.4346 \\
\hline Std. dev. & 0.4233 & 0.3214 & 0.6615 & 0.9769 & 0.6987 \\
\hline \multicolumn{6}{|l|}{ AV1 } \\
\hline mean & 4.5137 & 4.7721 & 4.1133 & 3.1933 & 3.9375 \\
\hline Std. dev. & 0.5036 & 0.7581 & 0.8903 & 0.7634 & 1.0072 \\
\hline \multicolumn{6}{|l|}{ AV2 } \\
\hline Mean & 4.6819 & 4.8006 & 4.0199 & 3.1805 & 3.9157 \\
\hline Std. dev. & 0.4658 & 0.523 & 0.8992 & 0.6537 & 0.7942 \\
\hline \multicolumn{6}{|l|}{ TR1 } \\
\hline Mean & 4.5994 & 4.997 & 4.3496 & 3.1376 & 4.0207 \\
\hline Std. dev. & 0.49 & 0.055 & 0.6684 & 0.977 & 0.6156 \\
\hline \multicolumn{6}{|l|}{ TR2 } \\
\hline Mean & 4.5138 & 4.8291 & 4.2904 & 3.3752 & 4.1476 \\
\hline Std. dev. & 0.6038 & 0.5056 & 0.6031 & 0.9856 & 0.6775 \\
\hline \multicolumn{6}{|l|}{ TR3 } \\
\hline mean & 4.6103 & 4.9145 & 4.1572 & 3.2465 & 4.2145 \\
\hline Std. dev. & 0.5344 & 0.2796 & 0.7849 & 0.7826 & 0.8061 \\
\hline \multicolumn{6}{|l|}{ RESP1 } \\
\hline Mean & 4.5831 & 4.997 & 4.1943 & 3.4461 & 4.2515 \\
\hline Std. dev. & 0.5341 & 0.0551 & 0.7273 & 1.0296 & 0.8713 \\
\hline
\end{tabular}


Table 7. Continued

\begin{tabular}{|c|c|c|c|c|c|}
\hline \multicolumn{6}{|c|}{ Cluster } \\
\hline RESP2 & & & & & \\
\hline Mean & 4.3224 & 4.8291 & 4.089 & 3.3472 & 4.5885 \\
\hline Std. dev. & 0.6193 & 0.3764 & 0.7288 & 0.7827 & 0.4932 \\
\hline \multicolumn{6}{|l|}{ RESP3 } \\
\hline Mean & 4.2957 & 4.9115 & 4.1092 & 3.6379 & 4.6282 \\
\hline Std. dev. & 0.6067 & 0.284 & 0.7383 & 0.6837 & 0.595 \\
\hline \multicolumn{6}{|l|}{ PERS1 } \\
\hline Mean & 4.2688 & 4.943 & 4.1939 & 3.2938 & 4.7131 \\
\hline Std. dev. & 0.6369 & 0.2318 & 0.6968 & 0.8983 & 0.4523 \\
\hline \multicolumn{6}{|l|}{ PERS2 } \\
\hline Mean & 4.1885 & 4.8006 & 4.2886 & 3.3813 & 4.1653 \\
\hline Std. dev. & 0.8405 & 0.3995 & 0.7551 & 0.9141 & 0.7715 \\
\hline \multicolumn{6}{|l|}{ PERS3 } \\
\hline Mean & 4.2433 & 4.883 & 4.371 & 3.6598 & 4.0592 \\
\hline Std. dev. & 0.5349 & 0.3214 & 0.6487 & 1.1185 & 1.0612 \\
\hline \multicolumn{6}{|c|}{ Clustered Instances } \\
\hline 0 & $32(21 \%)$ & & & & \\
\hline 1 & $39(26 \%)$ & & & & \\
\hline 2 & $46(30 \%)$ & & & & \\
\hline 3 & $19(13 \%)$ & & & & \\
\hline 4 & $15(10 \%)$ & & & & \\
\hline
\end{tabular}

Ahmad Abu-Al-Aish is an Assistant Professor in the Department of Computer Science, Faculty of Computer Science and Information Technology at Jerash University, Jordan. He received his PhD in Computer Science from Brunel University, United Kingdom in 2014. His Research interests including Electronic and Mobile Learning Systems, Algorithms, Combinatorial Optimization and Educational Data Mining Techniques. 